\title{
Correspondence
}

\section{Mental Health Act, 1983}

DEAR Sirs

I should like to join the debate, long continued in your correspondence pages, relating to the 1983 Mental Health Act. There are a number of recurring issues I will comment on, and one or two rarer ones that, nevertheless, are a cause for concern.

Broadly speaking, I view the 1983 Act as containing a number of welcome and liberal provisions, but also enshrined are some ominous overtones. Ominous is the provision for treatments that require consent and a second opinion (more of that later). Also there has been a distinct erosion of the RMO's powers without any commensurate recognition of this in terms of responsibility-how long will it be before an RMO refuses to remain responsible for a case that he cannot treat?

There are continuing problems concerning compulsory treatment in the community. Neither guardianship nor Section 3 provide the required degree of flexibility or control so essential for some patients. This issue has been raised vociferously by Peter Rohde, ${ }^{1}$ who has suggested solutions. Although I recently received a 'long and detailed document' entitled 'Consent to Treatment: Mental Health Act Commission', it does nothing to resolve this problem. It seems pertinent to 'our' move into the community that this problem is urgently addressed.

I was pleased to see the recommendations of the Royal College of Psychiatrists in relation to practice regarding consent. ${ }^{2}$ I have just visited the United States and feel that the use of the 'reasonable patient' as a standard can only lead inexorably to the practice of ultra-defensive medicine. The 'reasonable doctor', with the law courts as final arbiters, ought to help patients and doctors alike.

As for the issue of psychosurgery, ${ }^{3,4}$ although as one commissioner told me the problem, in numbers, is small, it is important in principle. Most of us can accept a second opinion from one of our peers-I am sure we often asked for such help from colleagues in the past and will in the future. Surely, though psychosurgery is a special case? The encouragement of specialised centres to carry out these procedures, as against a small number of operations dealt with in many centres, has an inevitable consequence. Few people see many cases, but these people develop a high degree of expertise, viz. Paul Bridges. Who can rightly claim to be a peer of his regarding psychosurgery-be it Mental Health Act commissioner or consultant psychiatrist? How helpful to a team with experience of over 1200 operations is a mandatory second opinion from a psychogeriatrician likely to be? How helpful is it likely to be to the patient? Lord Colville ${ }^{5}$ states that most medical commissioners are or were RMOs. This seems a dubious qualification-I am an RMO and I have had no direct experience with psychosurgery whatsoever. Lord Colville might find it hard to accept that 'with all the advice available to him the Secretary of State was so inept in his appointments of doctor commissioners that not one of them is fit to carry out the task imposed on them by the Act in relation to psychosurgery.' I do not.

I have been concerned at times to detain an informal depressed patient under Section 3 in order to obtain a second opinion to administer ECT without the patient's consent. It seems unfortunate to detain a patient who makes no attempt to leave hospital nor shows any desire whatsoever to do so. The problem arises from the difficulty of separating the concepts of 'need for detention' from the 'need for treatment'. I do understand that the appointed doctor cannot sign a treatment certificate under Section 58 in respect of an informal patient, ${ }^{6}$ but surely it would be possible to implement the Section 3 at the stage of the second opinion, if it is in accord with the RMO's treatment plan?

Recently, I have run into difficulties concerning the classification of psychotropic drugs. I believe the classification used by commissioners is that appearing in the British National Formulary. It appears that, despite sound research promoting carbamazepine's properties, the drug remains classed as an antiepileptic agent only. I have a patient on whom I have had a second opinion agreeing with antidepressant treatment, but have had to arrange for a further visit in order to have carbamazepine authorised. Fortunately, the commissioner was in accord. A further difficulty arises concerning lithium as well as carbamazepine administration. The Act allows for administration of these drugs but makes no provision to enable the RMO to carry out the essential monitoring required. I am, of course, referring the repeated blood samples in order to monitor the blood count with carbamazepine and serum levels with both drugs. I suppose one is covered by common law concerning this 'battery', but it seems an omission in the Act.

My final point, and what prompted me to put pen to paper, concerns automatic reviews by Mental Health Review Tribunals. I have a patient who unfortunately is a Huntington's Chorea sufferer. She is presently detained under Section 3. I write to report how distressed the patient and her family were at the time of her recent Mental Health Review Tribunal, which I must stress was automatic. Her husband is as supportive and caring a man as it is possible to meet. He managed her at home with no help as long as was humanly possible. She became increasingly violent and this necessitated her admission. The husband visits daily on the ward and takes her out at weekends. Nevertheless, there is no question of her discharge. Even prejudging the issue, there is no realistic hope that a Mental Health Review Tribunal would ever discharge her. She has recently been 'victim' of the 1983 Mental Health Act. The review itself was dealt with as 
sympathetically and humanely as possible by all concerned, especially Sir John Wood as Chairman of the Mental Health Review Tribunal. It was accepted that the safeguard of atuomatic reviews was aimed at the chronically detained schizophrenic patient who would not apply for a hearing. Nevertheless, it is law and applies indiscriminately to all detainees. It is regrettable that exceptions cannot be made. Othewise, if this unfortunate lady survives, there will be further distressing and 'futile' reviews ahead of her. Suggesting exceptions to the Act raises the issue of who should decide which cases should not be subject to repetitive and automatic reviews? The obvious answer, with all the advantages of impartiality, is the Mental Health Review Tribunal itself. The Mental Health Review Tribunal ought to have the power, in exceptional circumstances and at their discretion, to prevent further automatic reviews. Their powers were extended by the 1983 Act, why not extend the power to cover this unfortunate instance and similar ones.

Carlton Hayes Hospital

Narborough, Leicestershire.

\section{REFERENCE}

'RofDE, P. (1984) Compulsory treatment in the community: Is it authorised under the Mental Health Act 1983? Bulletin of the Royal College of Psychiatrists, 8, 148-151.

${ }^{2}$ Royal College of Psychiatrists (1985) Consent to psychiatric treatment for informal patients: College advice to psychiatrists. Bulletin of The Royal College of Psychiatrists, 9, 228-230.

${ }^{3}$ Brimges, P. (1984) Psychosurgery and the Mental Health Act Commission. Bulletin of the Royal College of Psychiatrists, 8 146-148.

4 - (1985) The Mental Health Act Commission and second opinions (Correspondence). Bulletin of the Royal College of Psychiatrists, 9, 120.

${ }^{5}$ Cotvirue, Lond (1985) The Mental Health Act Commission and socond opinions. Bulletin of the Royal College of Psychiatrists. 9,2-3.

${ }^{6}$ Fenron, T. W. (1984) The aftermath of the Mental Health Act 1983. Bulletin of the Royal College of Psychiatrists, 8, 190-193.

\section{Performance of foreign born candidates at the MRCPsych examinations}

Dear Sirs

I have been looking closely at the lists of successful candidates at both parts of the MRCPsych between 1976 and 1984, which are published in the Bulletin. I was alarmed and a bit surprised to see that British born candidates make up, on average, $73 \%$ of successful candidates in the Membership and Preliminary examinations. On this basis one could say that foreign born candidates have only one-third the chances of passing either exam as compared to British born entrants. However, this is assuming that equal numbers of British and foreign born doctors enter for the examination-but this is unlikely. Foreign born candidates usually out-number British born candidates, at least at London centres, by as much as two to one. This must mean that the real odds against a foreign doctor passing the exam at a given sitting is well near six to one. This is staggering in itself without also considering that many of the foreign doctors are taking the examination for the second or third time, and can hardly be called 'naive' candidates.

This appalling state of affairs has hardly been explained, although suggestions have been made that it may be due to poor English, unfamiliarity with the multiple choice format, or generally poor knowledge. The thinking seems to be that it is the last. ${ }^{1}$ In this light it is surprising that the College allows candidates to continue to sit for exams for which they are supposedly not ready, year after year. However, there is a further possibility, which people seem to shirk from, that foreign born candidates may be subject to discrimination in some way or another. The College allocates index numbers to candidates, but they do not seem to be used. Candidates have to write down their names and nationalities on a piece of paper in the examination room; they write their names on the answer sheet of MCQ paper; and during clinical and oral examinations, names, rather than index numbers, are used.

I suggest a few ideas which will reassure foreign doctors that they are being treated fairly. One suggestion is that index numbers should be used more realistically, and candidates' names should not be available to the panel that decides the list of successful candidates. Possible bias at clinical examinations is more difficult to eliminate, but by using index numbers exclusively, any bias in allocating candidates to patients may be avoided. A more radical move would be to change the status of the clinical examination, such that if a candidate passes both the essay and MCQ but fails the clinical, he should be required to re-sit the clinical only after six months, on payment of a further fee. He should only re-sit the whole examination if he fails a written paper as well.

I am not expecting that these ideas will be taken up avidly by the College, but if there is no discrimination, then I do not see what harm they can do. On the other hand, I think they will be vastly reassuring to the large number of foreign doctors who come to this country for training only to find that they are trapped in a miserable cycle of disillusionment and despair, with little prospect of their returning to their own countries with the qualification for which they came to Britain.

Farmborough Hospital

R. S. ONYANGo

Orpington, Kent

RERERENCE

${ }^{1}$ TrethowaN, W. (1982) The MRCPaych Examination: Time for change? Bulletin of the Royal College of Psychiatrists, 6, $174-176$

The Dean, Dr J. L. T. Birley, replies.

Many of the issues which Dr Onyango has raised are discussed in the report of the Trainees' Forum held last 